\title{
Clinical assessment and genomic landscape of a consanguineous family with three Kallmann syndrome descendants
}

\author{
Shi-Lin Zhang ${ }^{1}$, Yan-Ping Tang ${ }^{2}$, Tao Wang ${ }^{1}$, Jun Yang ${ }^{1}, K^{2}$ Rao ${ }^{1}$, Ling-Yun Zhao ${ }^{3}$, Wen-Zhen Zhu ${ }^{3}$, \\ Xiang-Hu Meng ${ }^{1}$, Shao-Gang Wang ${ }^{1}$, Ji-Hong Liu ${ }^{1}$, Wei-Min Yang ${ }^{1}$ and Zhang-Qun Ye ${ }^{1}$
}

Although some genes that cause Kallmann syndrome (KS) have been identified by traditional linkage analysis and candidate gene techniques, the syndrome's molecular etiology in the majority of patients remains poorly understood. In this paper, we present the clinical assessments of a consanguineous Han Chinese family with three KS descendants. To understand the molecular etiology of KS from a genome-wide perspective, we investigated the genome-wide profile of structural variation in this family using the Affymetrix Genome-Wide Human SNP Array 6.0 platform. The results revealed that the three affected individuals had common copy number variants (microdeletions) on chromosomes 1p21.1, 2q32.2, 8q21.13, 14q21.2 and Xp22.31. Moreover, the copy number variants on Xp22.31 were located in the intron of $K A L 1$, which causes X-linked KS. Two PCR assays were performed on these regions to validate the results obtained using the chips. In addition, genomic microdeletions in this region were verified in one of 29 Han Chinese sporadic KS cases and one of four other family cases, but not in $26 \mathrm{Han}$ Chinese sporadic normosmic idiopathic hypogonadotropic hypogonadism cases and 100 unrelated Han Chinese normal controls. Our results provide a novel insight into the relative contributions of certain copy number variants to KS's molecular etiology and generate a list of interesting candidate regions for further studies.

Asian Journal of Andrology (2011) 13, 166-171; doi:10.1038/aja.2010.83; published online 1 November 2010

Keywords: DNA copy number variations; hypogonadism; Kallmann syndrome; male infertility

\section{INTRODUCTION}

Kallmann syndrome (KS; OMIM: 308700), first described by Kallmann et al., ${ }^{1}$ is defined by the association of idiopathic hypogonadotropic hypogonadism (IHH) with complete (anosmia) or incomplete (hyposmia) olfaction disturbance. Estimates of its prevalence range from 1 in 8000 to 1 in 10000 men. ${ }^{2} \mathrm{IHH}$ is characterized by varying degrees of sexual development disruption, resulting in the failure to develop a mature reproductive system because of insufficient gonadotropin release for unknown reasons. When associated with anosmia or hyposmia, it is termed KS; however, IHH cases not associated with anosmia or hyposmia are denoted as normosmic IHH. Although previous work has implicated numerous genomic regions of interest, the identification of specific genetic variants that contribute to KS risk remains challenging. KAL1, the gene encoding the extracellular glycoprotein anosmin-1, is responsible for the $\mathrm{X}$ chromosome-linked recessive form of KS. Mutations in FGFR1 (KAL2), which encodes fibroblast growth factor receptor-1, underlie an autosomal dominant form with incomplete penetrance. These are the two major causative KS genes. ${ }^{3}$ FGF8, one of the 11 ligands of FGF signaling, was found to be mutated in 6 out of $461 \mathrm{IHH}$ patients. These patients exhibited varied degrees of olfactory function and gonadotropin-releasing hormone (GnRH) deficiency. ${ }^{4}$ Several novel genes-
CHD7, NELF, PROK2 and PROKR2-make excellent candidate genes for KS, as they are expressed in GnRH and olfactory neurons. ${ }^{5-7}$ However, all of these genetic abnormalities account for barely $30 \%$ of all KS cases. ${ }^{8}$ It is now believed that most people with KS have an unknown genetic defect. In humans, the term 'genomic disorders' includes the human genetic diseases caused by submicroscopic microdeletion or microduplication of a genomic region, often including copy number variation (CNV), which is a significant and ubiquitous source of inherited human genetic variation. $\mathrm{CNV}$ is observed in certain segments of DNA that can vary in length from one kilobase to several megabases. CNVs may be either inherited or caused by de novo mutation, which can be attributed to genomic rearrangements such as deletions, duplications, inversions and translocations. About $12 \%$ of the human genome contains deletions and duplications that may show CNVs, ${ }^{9}$ and a number of human diseases have been reported to be associated with CNVs. ${ }^{10-12}$ All disease-causing CNVs, whether they are inherited or de novo, can be collectively classified as copy number mutations. ${ }^{13}$ They may alter gene dosage, interrupt a gene or exert long-range positional effects on the expression pattern of the genes outside the CNV region, thereby producing the highly varied phenotypes seen in genomic disorders. ${ }^{14,15}$ With the application of modern high-resolution microarray-based technologies, numerous new geno- 
mic disorders have been uncovered. ${ }^{15,16}$ However, the importance of CNVs to KS susceptibility has not yet been explored.

In this study, we performed CNV analysis with the Affymetrix Genome-Wide Human SNP Array 6.0, which is effective for the identification of genomic CNVs and tests for more than 906600 singlenucleotide polymorphisms (SNPs) and 946000 copy number probes, in a Han Chinese KS family. ${ }^{10,17}$

The study also included a cohort with 29 sporadic and four family cases of KS, 26 sporadic cases of normosmic IHH and 100 normal controls.

\section{MATERIALS AND METHODS}

\section{Case presentations}

Informed consent was obtained from all participants, and the protocol was approved by the Ethics Committee of Tongji Hospital, Huazhong University of Science and Technology (Wuhan, China).

A consanguineous Han Chinese family with three affected descendants was diagnosed with KS and recruited for clinical and molecular genetic studies (Figure 1). The relevant history of the patients is described below, and Table 1 provides further details for the cases.

1. Case 1: subject II-1 (Figure 1) was a 23-year-old man who was referred because of sexual infantilism. His height was $178 \mathrm{~cm}$, his weight was $60 \mathrm{~kg}$ (BMI: $19 \mathrm{~kg} \mathrm{~m}^{-2}$ ) and his arm span was $186 \mathrm{~cm}$. Puberty had not occurred by the age of 18 years. He had a eunuchoid habitus and was unvirilized. Physical examination revealed the absence of facial hair and sparse pubic hair (Tanner stage 2). Penile length was $4 \mathrm{~cm}$ and testicular volume was $8 \mathrm{ml}$ (normal: 15$25 \mathrm{ml}$ ). There was no gynecomastia. A formal smell test revealed hyposmia. ${ }^{18} \mathrm{He}$ had no other physical abnormalities. Magnetic resonance imaging (MRI) of the head was normal except for dysplasia of the right olfactory bulb and the absence of the left olfactory bulb, olfactory tract and sulcus (Figure $2 \mathrm{c}$ ). The karyotype was 46,XY. As indicated in Table 2, the patient's basal serum testosterone concentration was $0.16 \mathrm{ng} \mathrm{ml}^{-1}$ (normal range: $1.75-$ $7.81 \mathrm{ng} \mathrm{ml}^{-1}$ ). The basal serum luteinizing hormone (LH) and follicle-stimulating hormone (FSH) concentrations were 0.11 and $0.22 \mathrm{mIU} \mathrm{ml}^{-1}$, respectively (normal ranges, 1.24-8.62 and 1.27$19.26 \mathrm{mIU} \mathrm{ml}^{-1}$, respectively) and increased normally in response to $\mathrm{GnRH}$ (100 $\mu \mathrm{g}$ administered intravenously): $\mathrm{LH}$ increased to $2.55 \mathrm{mIU} \mathrm{ml}^{-1}$ and FSH increased to $1.03 \mathrm{mIU} \mathrm{ml}^{-1}$. The results for growth hormone, prolactin, pituitary-thyroid and pituitaryadrenal function and glycolipid metabolism were normal. He had spermatorrhea a few times a month; semen analysis revealed very few sperm of poor quality (semen volume: $0.7 \mathrm{ml}$; sperm count: 45/high power objective; motility: grades $b$ and c).

2. Case 2: subject II-2 (twin of case 1; Figure 1) was also a patient with hypogonadism. Many of his findings were extremely similar to his

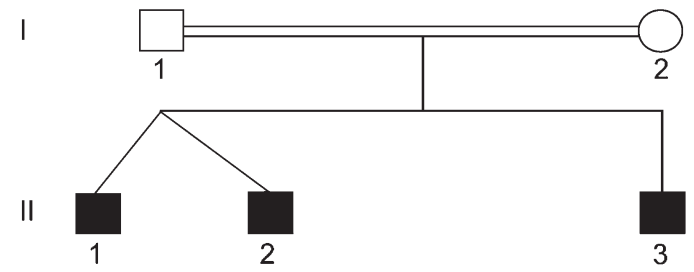

Figure 1 The consanguineous family tree with three Kallmann syndrome descendants. Solid symbols denote affected individuals; circles, female family members; squares, male family members; and double lines, consanguineous marriage. twin brother's. Except for the symptoms related to hypogonadism, he had no physical abnormalities. The results of his semen analysis were similar to those reported in case 1 (semen volume: $0.9 \mathrm{ml}$; sperm count: 4-6/high power objective; motility: grades b and c). Detailed information on the patient is presented in Tables 1 and 2.

3. Case 3: subject II-3 was the 19-year-old brother of cases 1 and 2 (Figure 1) whose puberty had not yet occurred by the age of 18 . Some results of his physical examination and endocrine and metabolism tests are shown in Tables 1 and 2, respectively. Compared with his two brothers, his symptoms seemed to be more severe. He was thinner than his brothers (body mass index, BMI: $14 \mathrm{~kg} \mathrm{~m}^{-2}$ ). Physical examination revealed the absence of facial hair and pubic hair (Tanner stage 1). A formal smell test revealed anosmia. The results of MRI revealed the absence of the olfactory bulb, olfactory tract and sulci (Figure 2d). The karyotype was $46, \mathrm{XY}$. He had no spontaneous spermatorrhea and was unable to masturbate to ejaculation.

The patients' mother, who was 46 years old (subject I-2 in Figure 1), had normal pubertal development and regular menstrual cycles. Her serum gonadotropin and estradiol concentrations were normal. The 48-year-old father of the patients (subject I-1 in Figure 1) was normally virilized, and his serum gonadotropin and testosterone concentrations were normal. Both parents' sense of smell and MRI results were normal (Figure 2a and b).

\section{Copy number mutation analysis}

Blood samples were obtained from the participating family members (three affected and two unaffected), and genomic DNA was subsequently extracted by standard methods.

The genome-wide linkage scan was carried out first. DNA samples were genotyped with an Affymetrix Genome-Wide Human SNP Array 6.0 (Affymetrix Inc., Santa Clara, CA, USA) containing more than 906600 SNPs and 946000 copy number probes. Genomic DNA samples were genotyped with the SNP Array 6.0 in accordance with the manufacturer's protocols. The Affymetrix GeneChip Operating Software (Affymetrix) was used for image processing. Genotypes were determined using the Affymetrix GeneChip Genotyping Analysis Software (GTYPE 4.0). Non-parametric multipoint linkage analysis was performed with the dChipLinkage software (Affymetrix) under the assumptions of autosomal recessive inheritance and X-linked recessive inheritance with $98 \%$ penetrance, a disease allele frequency of $0.1 \%$ and equal SNP allele frequency (50\%). Mendelian errors, unlikely genotypes and minor allele frequencies $<0.01$ in Han Chinese were deleted before linkage analysis.

Subsequently, the CNV were analyzed with the same Affymetrix Genome-Wide Human SNP Array 6.0. The Affymetrix Genotyping Console 3.0 software was used for genotype calling, quality control and $\mathrm{CNV}$ identification. Copy number state calls were determined with the Canary algorithm embedded in the Affymetrix Genotyping Console 3.0 package.

\section{PCR and electrophoresis experiments}

Validation of the microdeletion polymorphisms was carried out by PCR amplification using two paired primers set within the deleted Xp22.31 genomic regions. Primers were designed using the Primer Express 5.0 software (Applied Biosystems, Foster City, CA, USA) and synthesized by Shanghai Invitrogen Biotechnology Co. Ltd (Shanghai, China). Information about the primers and amplicon positions is as follows: S1 (CNV position: 8612924-8613985) F: 5' TCGACGAAGGGAGTCCAGGCA-3' and S1R: 5' -GAGCCTGGGGT 
Table 1 Physical examination and MRI findings of the three KS brothers and their parents

\begin{tabular}{|c|c|c|c|c|c|c|c|c|c|c|c|c|}
\hline \multirow{2}{*}{ Case } & \multirow{2}{*}{$\begin{array}{c}\text { Age } \\
\text { (years) }\end{array}$} & \multirow{2}{*}{ Sex } & \multirow{2}{*}{$\begin{array}{l}\text { Height } \\
(\mathrm{cm})\end{array}$} & \multirow{2}{*}{$\begin{array}{l}\text { Weight } \\
(\mathrm{kg})\end{array}$} & \multirow{2}{*}{$\begin{array}{l}\text { Arm span } \\
\quad(\mathrm{cm})\end{array}$} & \multirow{2}{*}{$\begin{array}{c}\text { Pubic hair } \\
\text { (Tanner stage) }\end{array}$} & \multirow{2}{*}{$\begin{array}{c}\text { Testicular } \\
\text { volume (ml) }\end{array}$} & \multirow{2}{*}{$\begin{array}{l}\text { Penis length } \\
\quad(\mathrm{cm})\end{array}$} & \multirow{2}{*}{$\begin{array}{l}\text { Smell } \\
\text { test }\end{array}$} & \multirow{2}{*}{ Karyotype } & \multicolumn{2}{|c|}{ MRI findings } \\
\hline & & & & & & & & & & & $O T$ & $O B$ \\
\hline ॥-1 & 23 & M & 178 & 60 & 186 & 2 & 8 & 4 & $\mathrm{H}$ & $46, X Y$ & $\mathrm{~L} \rightarrow \mathrm{AB}$ & $\mathrm{R} \rightarrow \mathrm{D}$ \\
\hline \multirow[t]{2}{*}{$\|-2$} & 23 & $M$ & 178 & 62 & 186 & 2 & 8.5 & 4 & $\mathrm{H}$ & $46, X Y$ & $L \rightarrow A B$ & $\mathrm{R} \rightarrow \mathrm{D}$ \\
\hline & & & & & & & & & & & $L \rightarrow A B$ & $\mathrm{R} \rightarrow \mathrm{D}$ \\
\hline $11-3$ & 19 & $M$ & 172 & 42 & 172 & 1 & 6 & 3.5 & AN & $46, X Y$ & $A B$ & $A B$ \\
\hline
\end{tabular}

Abbreviations: AB, absent; AN, anosmia; D, dysplasia; F, female; H, hyposmia; KS, Kallmann syndrome; L, left; M, male; MRI, magnetic resonance imaging; N, normal; NM, not measured; OB, olfactory bulb; OT, olfactory tract and sulcus; R, right; -, no item for checking.
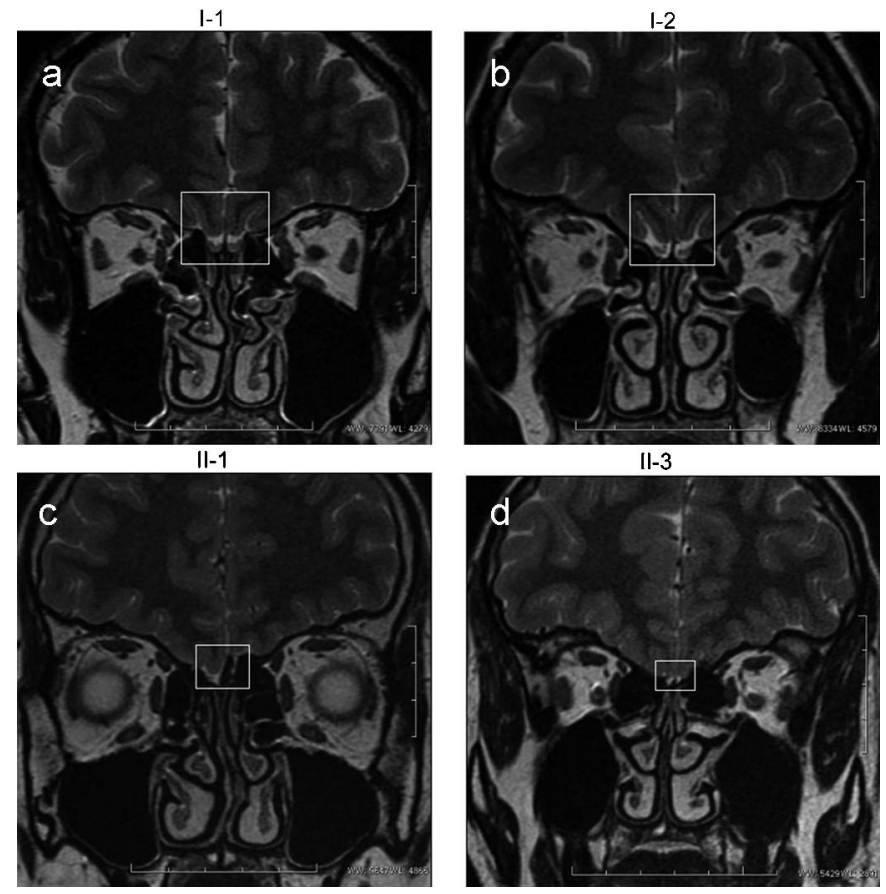

Figure $2 \mathrm{MRI}$ findings of the patients and their parents. (a, b) T2-W MR images show normal structures in the parents (I-1 and I-2, squares). (c) The MRI shows dysplasia of the right olfactory bulb as well as the absence of the left olfactory bulb, olfactory tract and sulcus (squares) in patient II-1. (d) It also shows the absence of the olfactory bulb, olfactory tract and sulci in patient II-3. As the MRI findings of patient II-2 were similar to those of the patient II-1, they are not shown here. MRI, magnetic resonance imaging.

CTGAGGGGC-3'; S2 (CNV position: 8611093-8611616) F: 5' -TGAA AGAATTGGCACTCAGTGAACTCC-3' and S2R: 5'-GGGCCCAAC TTATTAATGCAACACA- $3^{\prime}$. The annealing temperatures were 63 and $60^{\circ} \mathrm{C}$ for S1 and S2, respectively. The amplified products were 172 and $192 \mathrm{bp}$ long for S1 and S2, respectively. Reactions were performed on genomic DNA samples with a total $50 \mu \mathrm{l}$ reaction volume containing $25 \mu \mathrm{l}$ of $2 \times$ PCR Master Mix (Tiangen Biotech, Beijing, China), 10 pmol forward and reverse primers and $50 \mathrm{ng}$ genomic DNA. The incubation was carried out at $94^{\circ} \mathrm{C}$ for $5 \mathrm{~min}$, followed by 35 cycles at $94^{\circ} \mathrm{C}$ for $1 \mathrm{~min}, 63$ or $60^{\circ} \mathrm{C}$ for $1 \mathrm{~min}$ and $72^{\circ} \mathrm{C}$ for $1 \mathrm{~min}$, in an Eppendorf Mastercycler (Eppendorf AG, Hamburg, Germany). All PCR products were examined by electrophoresis on $2.0 \%$ agarose and Golden View I gels and photographed with an Alpha Innotech Imager (Alpha Innotech, San Leandro, CA, USA). To confirm whether the KS phenotype is associated with a recurrent microdeletion on
Xp22.31, we performed PCR amplification with these primers (S1 and S2) in 29 Han Chinese sporadic KS cases, four family KS cases, 26 Han Chinese sporadic normosmic IHH cases and 100 unrelated Han Chinese normal controls. The experiments were repeated three times.

Mutational analysis of the KAL1 and FGFR1 genes

As the X-linked KAL1 gene and FGFR1 (KAL2) gene, which are involved in an autosomal dominant form, are the two major causative KS genes, ${ }^{3}$ it was necessary to determine whether any changes in these genes could be observed. Exons and exon/intron boundaries were amplified using standard PCR techniques for KAL1 (GenBank accession no. NM_000216) and FGFR1 (GenBank accession no. NM_001174067), and purified using a PCR Product Purification Kit (Tiangen Biotech). Direct sequencing of the PCR products was carried out in both directions using the ABI PrismBig Dye terminator cycle sequencing ready reaction version 2.0 (Applied Biosystems) in an ABI Prism 3100 DNA Sequencer (PerkinElmer/Applied Biosystems). The primers and programs used for KAL1 and FGFR1 coding exon analysis have been published elsewhere. ${ }^{19,20}$

\section{RESULTS}

In this study, we used high-density SNP genotype data to identify structural variants in the KS pedigree, and our multipoint linkage analysis produced maximum logarithm of the odds scores of 0.98 with markers on chromosome 4 and 0.65 with markers on chromosome X, neither of which was statistically significant. However, our CNV analysis implied that, unlike their parents, the three affected individuals had common CNVs (microdeletions) on chromosomes 1p21.1, 2p32.2, 8q21.13, 14q21.2 and Xp22.31 (Table 3). Further analysis revealed that microdeletions on Xp22.31 were located in the intron region of the KAL1 gene (Figure 3). The results of the chips were validated by the two pairs of PCR primers for this region ( $\mathrm{S} 1$ and S2). Microdeletion was detected in one of 29 Han Chinese sporadic KS cases and one of four family cases by primer S2, and was not detected in 26 Chinese Han sporadic IHH cases and 100 unrelated Han Chinese normal controls. However, no microdeletions were found using primer S1 among these groups of cases. No mutations were found in the three patients or their parents by mutational analysis of exons and exon/intron boundaries in the KAL1 and FGFR1 genes.

\section{DISCUSSION}

KS, which traditionally presents with a lack of sexual maturation by age 18 , is associated with low gonadotropins and no anatomical reason for this failure of sexual maturation. ${ }^{21} \mathrm{KS}$ is a heterogeneous developmental genetic disorder, with the majority of cases being sporadic. ${ }^{22}$ To date, our understanding of the components of the complex developmental biology 
Table 2 Evaluation of somatotropic, gonadotropic, thyrotropic, corticotropic and glucose and fat metabolism functions in three affected brothers with KS

\begin{tabular}{|c|c|c|c|c|c|c|c|c|c|c|c|}
\hline Case & $\begin{array}{c}G H, B / P \\
\left(n g m l^{-1}\right)\end{array}$ & $\begin{array}{c}L H, B / P \\
\left(m / \cup m l^{-1}\right)\end{array}$ & $\begin{array}{c}F S H, B / P \\
\left(m / \cup m l^{-1}\right)\end{array}$ & $\begin{array}{c}E 2 \\
\left(p g m l^{-1}\right)\end{array}$ & $\begin{array}{c}T \\
\left(n g m l^{-1}\right)\end{array}$ & $\begin{array}{c}\text { ACTH } \\
\left(\mathrm{pg} \mathrm{ml^{-1 }}\right)\end{array}$ & $\begin{array}{c}\text { TT3 } \\
\left(\mathrm{nmol} \Gamma^{-1}\right)\end{array}$ & $\begin{array}{c}\text { TT4 } \\
\left(n m o l I^{-1}\right)\end{array}$ & $\begin{array}{c}T S H \\
\left(m I U I^{-1}\right)\end{array}$ & $\begin{array}{c}T G \\
\left(n m o l I^{-1}\right)\end{array}$ & $\begin{array}{c}\mid R I \\
\left(m \mid \cup I^{-1}\right)\end{array}$ \\
\hline$\|-1$ & $0.7 / 8.64$ & $0.11 / 2.55$ & $0.22 / 1.03$ & $0-20$ & 0.16 & 32.5 & 2.19 & 125 & 3.35 & 0.58 & 4.08 \\
\hline $11-2$ & $0.78 / 8.25$ & $0.19 / 2.62$ & $0.67 / 1.58$ & $0-20$ & 0.19 & 30.2 & 1.89 & 72.8 & 1.75 & 0.87 & 7.55 \\
\hline $11-3$ & $0.65 / 8.55$ & $0.1 / 1.36$ & $0.24 / 1.32$ & 29.3 & 0.25 & 34.4 & 2.37 & 144 & 1.02 & 1.20 & 12.5 \\
\hline
\end{tabular}

Abbreviations: ACTH, adreno-cortico-tropic-hormone; E2, estradiol; FSH, follicle-stimulating hormone; IRI, immunoreactiveinsulin; LH, luteinizing hormone; N, normal range. T, testosterone; TG, Triglyceride; TSH, thyroid stimulating hormone; TT3, total triiodothyronine; TT4, total thyroxine.

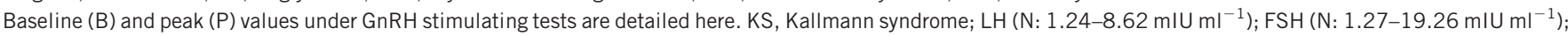

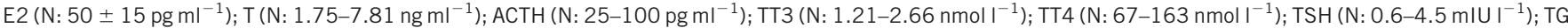
(N: 0.45-1.80 $\left.\mathrm{mmol} \mathrm{I}^{-1}\right)$; IRI (N: 0-22.02 $\mathrm{mIU} \mathrm{I}^{-1}$ ).

Table 3 The common CNVs (microdeletions) on chromosomes 1p21.1, 2p32.2, 8q21.13, 14q21.2 and Xq22.31 in the three brothers with KS

\begin{tabular}{|c|c|c|c|c|c|c|c|c|c|}
\hline ProbeSet & Chr & Position & CNState I-1 & CNState II-1 & CNState II-2 & CNState II-3 & CNState I-2 & Strand & Cytoband \\
\hline CN_438418 & 1 & 105634724 & 2 & 0 & 0 & 0 & 2 & + & p21.1 \\
\hline CN_438419 & 1 & 105638840 & 2 & 0 & 0 & 0 & 2 & + & p21.1 \\
\hline SNP_A-8345745 & 1 & 105637253 & 2 & 0 & 0 & 0 & 2 & - & p21.1 \\
\hline SNP_A-8496679 & 1 & 105634384 & 2 & 0 & 0 & 0 & 2 & - & p21.1 \\
\hline CN_438421 & 1 & 105641623 & 2 & 0 & 0 & 0 & 2 & + & p21.1 \\
\hline CN_438420 & 1 & 105641507 & 2 & 0 & 0 & 0 & 2 & + & p21.1 \\
\hline SNP_A-2158374 & 1 & 105639818 & 2 & 0 & 0 & 0 & 2 & + & $\mathrm{p} 21.1$ \\
\hline CN_818251 & 2 & 190216325 & 2 & 0 & 0 & 0 & 2 & + & q32.2 \\
\hline SNP_A-1966264 & 2 & 190216292 & 2 & 0 & 0 & 0 & 2 & - & q32.2 \\
\hline SNP_A-8385754 & 8 & 83480032 & 2 & 1 & 1 & 1 & 2 & - & q21.13 \\
\hline SNP_A-8372742 & 8 & 83461850 & 2 & 1 & 1 & 1 & 2 & - & q21.13 \\
\hline CN_1271156 & 8 & 83472822 & 2 & 1 & 1 & 1 & 2 & + & q21.13 \\
\hline SNP_A-1866241 & 8 & 83461664 & 2 & 1 & 1 & 1 & 2 & + & q21.13 \\
\hline SNP_A-2289787 & 8 & 83470054 & 2 & 1 & 1 & 1 & 2 & + & q21.13 \\
\hline CN_1271150 & 8 & 83457338 & 2 & 1 & 1 & 1 & 2 & + & q21.13 \\
\hline CN_1271151 & 8 & 83460123 & 2 & 1 & 1 & 1 & 2 & + & q21.13 \\
\hline CN_1271152 & 8 & 83461688 & 2 & 1 & 1 & 1 & 2 & + & q21.13 \\
\hline CN_1271154 & 8 & 83466820 & 2 & 1 & 1 & 1 & 2 & + & q21.13 \\
\hline CN_1271155 & 8 & 83471049 & 2 & 1 & 1 & 1 & 2 & + & q21.13 \\
\hline CN_1271157 & 8 & 83476395 & 2 & 1 & 1 & 1 & 2 & + & q21.13 \\
\hline CN_1271158 & 8 & 83480089 & 2 & 1 & 1 & 1 & 2 & + & q21.13 \\
\hline CN_375572 & 8 & 83469148 & 2 & 1 & 1 & 1 & 2 & + & q21.13 \\
\hline SNP_A-8702994 & 8 & 83461577 & 2 & 1 & 1 & 1 & 2 & + & q21.13 \\
\hline SNP_A-8363577 & 14 & 21656002 & 2 & 1 & 1 & 1 & 2 & - & q11.2 \\
\hline SNP_A-8355050 & 14 & 21676090 & 2 & 1 & 1 & 1 & 2 & - & $\mathrm{q} 11.2$ \\
\hline SNP_A-1831970 & 14 & 21675586 & 2 & 1 & 1 & 1 & 2 & - & $\mathrm{q} 11.2$ \\
\hline SNP_A-8610055 & 14 & 21656444 & 2 & 1 & 1 & 1 & 2 & + & $\mathrm{q} 11.2$ \\
\hline CN_635975 & 14 & 21662455 & 2 & 1 & 1 & 1 & 2 & + & $\mathrm{q} 11.2$ \\
\hline CN_635976 & 14 & 21664305 & 2 & 1 & 1 & 1 & 2 & + & $\mathrm{q} 11.2$ \\
\hline SNP_A-1871960 & 14 & 21660836 & 2 & 1 & 1 & 1 & 2 & - & $\mathrm{q} 11.2$ \\
\hline CN_635979 & 14 & 21671661 & 2 & 1 & 1 & 1 & 2 & + & $\mathrm{q} 11.2$ \\
\hline SNP_A-4194369 & 14 & 21674996 & 2 & 1 & 1 & 1 & 2 & + & $\mathrm{q} 11.2$ \\
\hline CN_635977 & 14 & 21668322 & 2 & 1 & 1 & 1 & 2 & + & $\mathrm{q} 11.2$ \\
\hline SNP_A-2293117 & 14 & 21671771 & 2 & 1 & 1 & 1 & 2 & + & $\mathrm{q} 11.2$ \\
\hline SNP_A-1822934 & 14 & 21664286 & 2 & 1 & 1 & 1 & 2 & - & $\mathrm{q} 11.2$ \\
\hline CN_635981 & 14 & 21675712 & 2 & 1 & 1 & 1 & 2 & + & $\mathrm{q} 11.2$ \\
\hline CN_635980 & 14 & 21672385 & 2 & 1 & 1 & 1 & 2 & + & $\mathrm{q} 11.2$ \\
\hline SNP_A-8415044 & 14 & 21662834 & 2 & 1 & 1 & 1 & 2 & + & $\mathrm{q} 11.2$ \\
\hline SNP_A-8456863 & 14 & 21656232 & 2 & 1 & 1 & 1 & 2 & - & $\mathrm{q} 11.2$ \\
\hline SNP_A-2269660 & 14 & 21660717 & 2 & 1 & 1 & 1 & 2 & + & $\mathrm{q} 11.2$ \\
\hline SNP_A-8571070 & $x$ & 8613317 & 1 & 0 & 0 & 0 & 2 & + & p22.31 \\
\hline SNP_A-8518956 & $x$ & 8611479 & 1 & 0 & 0 & 0 & 2 & - & p22.31 \\
\hline SNP_A-2178236 & $x$ & 8611505 & 1 & 0 & 0 & 0 & 2 & + & p22.31 \\
\hline CN_974182 & $x$ & 8611596 & 1 & 0 & 0 & 0 & 2 & + & p22.31 \\
\hline CN 974184 & $x$ & 8611870 & 1 & 0 & 0 & 0 & 2 & + & p22.31 \\
\hline
\end{tabular}

Abbreviation: Chr, chromosome.

In terms of autosome and X autosome in female CNState: 0 (double deletion), 1 (single deletion), 2 (wild type), 3 (single duplicate), 4 (double duplicate); in terms of X autosome in male CNState: 0 (deletion), 1 (wild type), 2-4 (duplicate). 


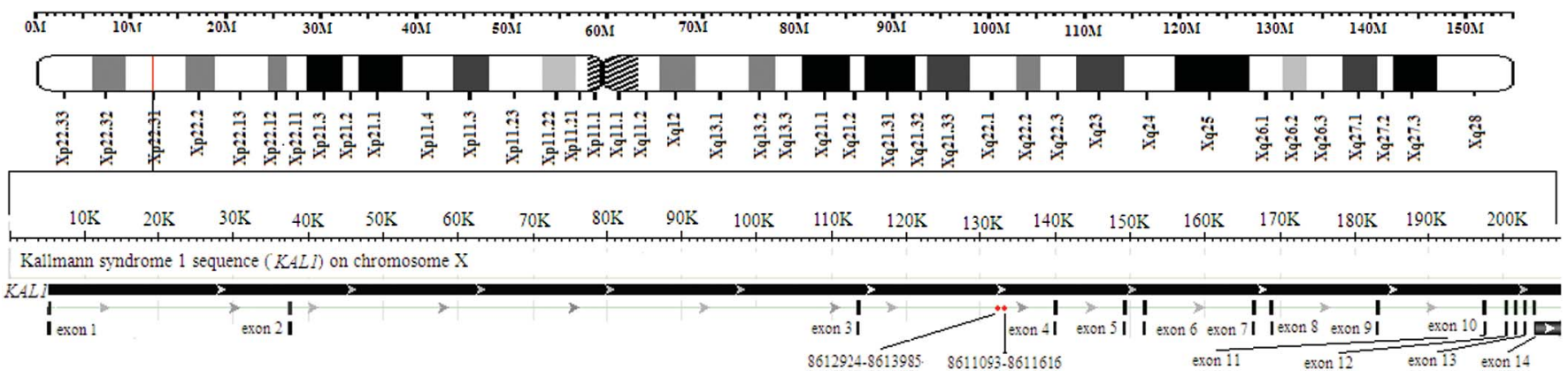

Figure 3 Locations of the microdeletion on the X chromosome. Red line, microdeletion on the X chromosome and red dots, microdeletion in the intron of $K A L 1$.

of KS and its genetic control has remained limited. KAL1 was the first gene discovered to be a critical determinant of KS in a patient who had a contiguous gene syndrome associated with a deletion of the Xp21 region. ${ }^{23}$ Mutations in KAL1 account for $33-70 \%$ of familial cases of KS and 3.1-27.8\% of apparently sporadic forms of $\mathrm{IHH}$ with anosmia. ${ }^{20,24,25}$ Mutations in KAL1 have also been found in Han Chinese KS patients. ${ }^{26}$ Mutations in the FGFR1 gene, the major causative gene in the autosomal dominant form of KS, have been shown to account for roughly $10 \%$ of cases of $\mathrm{KS}^{20}{ }^{20}$ Loss-of-function mutations in PROKR2 or PROK2 have been found in $9 \%$ of KS patients, most of which were heterozygous; however, homozygous and compound heterozygous mutations have also been described. ${ }^{7}$ CHD7 encodes a chromatin-remodeling factor and is defective in CHARGE syndrome, which includes colobomata, heart anomalies, choanal atresia, retardation, genital and ear anomalies and sometimes IHH and hyposmia. ${ }^{5}$ The NELF gene encoding the nasal embryonic luteinizing hormone-releasing hormone factor has been identified as a strong candidate gene for KS on the basis of its characterization as an axon guidance factor in murine GnRH neurons, but no relevant functional studies have been reported. ${ }^{6}$ All of these genes account for a minority of all cases of KS. Genetic tools such as linkage, animal knockouts and mapping of chromosomal breakpoints associated with phenotypes have proven to be unique biological opportunities to understand the spectrum of KS in humans. However, rare single-gene variations do not explain all of the findings within KS—whole-genome-based analyses may yield more comprehensive and accurate information.

$\mathrm{CNV}$ s are a source of genetic diversity in humans. Numerous CNVs are being identified with various genome analysis platforms, including array comparative genomic hybridization, SNP genotyping platforms and next-generation sequencing. The structural variation in an individual genome includes thousands of discrete regions, spans millions of base pairs and encompasses numerous entire genes and their regulatory regions. By various molecular mechanisms, such variation results in absent or altered gene expression and subsequently leads to phenotypic changes, disease susceptibility, Mendelian or sporadic traits or complex diseases. ${ }^{9}$ Therefore, research on genomic structural variation is useful for analyzing the integrated genotype with genomic variation and understanding the potential medical effects of such variation. In this study, we carried out a genome-wide linkage scan in a KS-affected family using the Affymetrix Genome-Wide Human SNP Array 6.0 and revealed that the three affected individuals had common CNVs (microdeletions) on chromosomes 1p21.1, 2p32.2, 8q21.13, $14 q 21.2$ and Xp22.31. Further analysis showed that the CNVs on $\mathrm{Xp22.31}$ were located in the intron of KAL1, which causes X-linked KS.

Although we found that the deletions on chromosome Xp22.31 were in the intron, the observation of common microdeletions by
PCR in the three affected brothers, as well as in one of 29 Han Chinese sporadic KS cases and one of four family cases, implies that the observation of these microdeletions in the three affected brothers was not an isolated incident. Orozco et al. ${ }^{27}$ showed that CNVs influence gene expression and metabolic traits in mice. The expression of most CNV genes was correlated with copy number, but these researchers also reported evidence that gene expression was altered in genes flanking $\mathrm{CNVs}$, suggesting that $\mathrm{CNVs}$ may contain regulatory elements for these genes. A major challenge in current genome biology is to reveal the biological significance of the many evolutionary conserved noncoding sequences. The analysis of the functional significance of evolutionary conserved noncoding sequences is hindered by a paucity of mutations in such regions that show an association with a phenotype. ${ }^{28}$ Here, we showed that the rich abundance of evolutionary conserved noncoding sequences mutations in the KAL1 region is likely to be associated with the KS phenotype. However, much more work is needed to determine the real cause of KS.

In brief, KS may be the result of multiple genes working together. Although no significant linkage analysis sites were found, possibly as a result of the small family sample size, we found many interesting CNVs. The region of the common CNVs (microdeletions) contains a large number of genes, such as ZNF182 on Xp11.23, LOC642337 (similar to hCG1648021) on 1p21.1 and LOC644662 (similar to hCG2042541) downstream of 3q21.2. Of particular interest, ZNF182 is a zinc finger protein that is a sequence-specific transcriptional repressor involved in a special intracellular nucleic acid binding, control of gene expression and cell division and differentiation, embryonic development and later growth. Could these microdeletions potentially contribute to the development of IHH/KS? A further study with a larger number of cases would be necessary to test this claim. In addition, consanguinity is likely to increase the risk of autosomal recessive diseases. Point mutations in this X-linked KAL1 gene were not shown, providing more clear evidence for an autosomal locus in this family. The autosomal locus of the copy number deletions and the relationship between the CNVs and the KS phenotype should be the focus of further study.

\section{AUTHOR CONTRIBUTIONS}

JHL designed research; SLZ, YPT, TW, JY, performed research; LYZ, WZZ, performed MRI test; KR, XHM, SGW, WMY, ZQY, participated in the selection of patients and normal subjects; JHL and SLZ wrote the paper.

\section{COMPETING FINANCIAL INTERESTS}

The authors declare no competing financial interests. 


\section{ACKNOWLEDGMENTS}

We thank the patients and the family for their cooperation in this study. We thank Shanghai Biochip Co. Ltd for offering the Affymetrix Genome-Wide Human SNP Array 6.0 chips and helping with the chip data analysis.

1 Kallmann FJ, Schoenfeld WA, Barrera SE. The genetic aspects of primary eunuchoidism. Am J Ment Defic 1944; 158: 203-36.

2 Seminara SB, Hayes FJ, Crowley WF Jr. Gonadotropin-releasing hormone deficiency in the human (idiopathic hypogonadotropic hypogonadism and Kallmann's syndrome) pathophysiological and genetic considerations. Endocr Rev 1998; 19: 521-39.

3 Salenave S, Chanson P, Bry H, Pugeat M, Cabrol S et al. Kallmann's syndrome: a comparison of the reproductive phenotypes in men carrying KAL1 and FGFR1/KAL mutations. J Clin Endocrinol Metab 2008; 93: 758-63.

4 Falardeau J, Chung WC, Beenken A, Raivio T, Plummer L et al. Decreased FGF8 signaling causes deficiency of gonadotropin-releasing hormone in humans and mice. J Clin Invest 2008; 118: 2822-31.

5 Pinto G, Abadie V, Mesnage R, Blustajn J, Cabrol S et al. CHARGE syndrome includes hypogonadotropic hypogonadism and abnormal olfactory bulb development. J Clin Endocrinol Metab 2005; 90: 5621-6.

6 Miura K, Acierno JS Jr, Seminara SB. Characterization of the human nasal embryonic LHRH factor gene, NELF, and a mutation screening among 65 patients with idiopathic hypogonadotropic hypogonadism (IHH). J Hum Genet 2004; 49: 265-8.

7 Dodé C, Teixeira L, Levilliers J, Fouveaut C, Bouchard P et al. Kallmann syndrome: mutations in the genes enconding prokineticin-2 and prokineticin receptor-2. PLoS Genet 2006; 2: e175.

8 Hardelin JP, Dodé C. The complex genetics of Kallmann syndrome: KAL1, FGFR1, FGF8, PROKR2, PROK2, et al. Sex Dev 2008; 2: 181-93.

9 Zhang F, Gu W, Hurles ME, Lupski JR. Copy number variation in human health, disease, and evolution. Annu Rev Genomics Hum Genet 2009; 10: 451-81.

10 Redon R, Ishikawa S, Fitch KR, Feuk L, Perry GH et al. Global variation in copy number in the human genome. Nature 2006; 444: 444-54.

11 Beckmann JS, Estivill X, Antonarakis SE. Copy number variants and genetic traits: close to the resolution of phenotypic to genotypic variability. Nat Rev Genet 2007; 8: 639-46.

12 Cook EH Jr, Scherer SW. Copy-number variations associated with neuropsychiatric conditions. Nature 2008; 455: 919-23.
13 Sun M, Li N, Dong W, Chen Z, Liu Q et al. Copy-number mutations on chromosome 17q24.2-q24.3 in congenital generalized hypertrichosis terminalis with or without gingival hyperplasia. Am J Hum Genet 2009; 84: 1-7.

14 Lupski JR, Stankiewicz P. Genomic disorders: molecular mechanisms for rearrangements and conveyedphenotypes. PLoS Genet 2005; 1: e49.

15 Sharp AJ. Emerging themes and new challenges in defining the role of structural variation in human disease. Hum Mutat 2009, 30: 135-44.

16 Lupski JR. Genomic rearrangements and sporadic disease. Nat Genet2007; 39: S43-7.

17 Komura D, Shen F, Ishikawa S, Fitch KR, Chen W et al. Genome-wide detection of human copy number variations using high-density DNA oligonucleotide arrays. Genome Res 2006; 16: 1575-84.

18 Good KP, Martzke JS, Daoud MA, Kopala LC. Unirhinal norms for the University of Pennsylvania Smell Identification Test. Clin Neuropsychol 2003; 17: 226-34.

19 Hardelin JP, Levilliers J, Blanchard S, Carel JC, Leutenegger M et al. Heterogeneity in the mutations responsible for $\mathrm{X}$ chromosome-linked Kallmann syndrome. Hum $\mathrm{Mol}$ Genet 1993; 2: 373-7.

20 Sato N, Katsumata N, Kagami M, Hasegawa T, Hori N et al. Clinical assessment and mutation analysis of Kallmann syndrome 1 (KAL1) and fibroblast growth factor receptor 1 (FGFR1, or KAL2) in five families and 18 sporadic patients. J Clin Endocrinol Metab 2004; 89: 1079-88.

21 Crowley WF Jr, Pitteloud N, Seminara S. New genes controlling human reproduction and how you find them. Trans Am Clin Climatol Assoc 2008; 119: 29-38.

$22 \mathrm{Hu}$ Y, Tanriverdi F, MacColl GS, Bouloux PM. Kallmann's syndrome: molecular pathogenesis. Int J Biochem Cell Biol 2003; 35: 1157-62.

23 Bick D, Franco B, Sherins RJ, Heye B, Pike L et al. Brief report: intragenic deletion of the KALIG-1 gene in Kallmann's syndrome. N Eng/ J Med 1992; 326: 1752-5.

24 Dode C, Levilliers J, Dupont JM, de Paepe A, le Dû N et al. Loss-of-function mutations in FGFR 1 cause autosomal dominant Kallmann syndrome. Nat Genet 2003; 33: 463-5.

25 Pitteloud N, Acierno JS Jr, Meysing A, Eliseenkova AV, Ma J et al. Mutations in fibroblast growth factor receptor 1 cause both Kallmann syndrome and normosmic idiopathic hypogonadotropic hypogonadism. Proc Natl Acad Sci USA 2006; 103: 6281-6.

26 Tang KF, Wu QF, Zou TJ, Xue W, Wang XY et al. Molecular analysis of KAL-1 in a series of Kallmann syndrome and normosmic idiopathic hypogonadotropic hypogonadism patients from Northwestern China. Asian J Androl 2009; 11: 711-5.

27 Orozco LD, Cokus SJ, Ghazalpour A, Ingram-Drake L, Wang S et al. Copy number variation influences gene expression and metabolic traits in mice. Hum Mol Genet 2009; 18: 4118-29.

28 Wright D, Boije H, Meadows JR, Bed'hom B, Gourichon D et al. Copy number variation in Intron 1 of SOX 5 causes the pea-comb phenotype in chickens. PLoS Genet 2009; 5 e1000512. 